Johannes M. Ruschke

\title{
Paul Gerhardt und der Berliner Kirchenstreit
}

Eine Untersuchung der konfessionellen Auseinandersetzungen über die kurfürstlich verordnete 'mutua tolerantia'

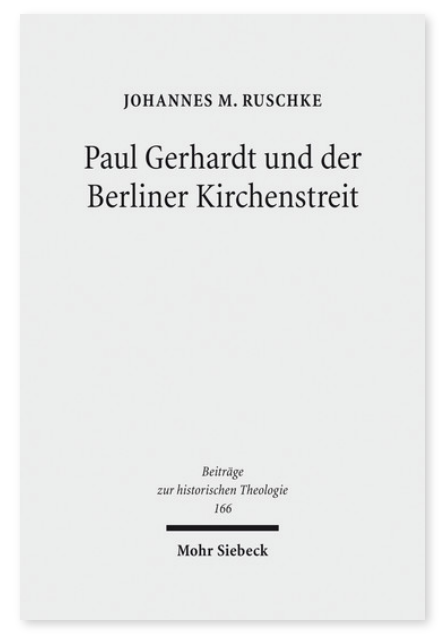

2012. XVIII, 624 Seiten. BHTh 166

ISBN 978-3-16-152014-3

DOI 10.1628/978-3-16-152014-3

eBook PDF $144,00 €$

ISBN 978-3-16-150952-0

Leinen 144,00
Paul Gerhardt gilt neben Martin Luther als bedeutendster evangelischer Liederdichter. Im Berliner Kirchenstreit, den konfessionellen Auseinandersetzungen zwischen lutherischen und reformierten Theologen bzw. zwischen lutherischen Untertanen und dem reformiert geprägten kurfürstlich-brandenburgischen Hof in der zweiten Hälfte des 17. Jahrhunderts, spielte Gerhardt eine entscheidende Rolle. Als Vertreter einer strengen lutherischen Orthodoxie lehnte er jeden obrigkeitsgesteuerten Versuch ab, Konflikte zwischen den Konfessionen zu beenden und eine gegenseitige Toleranz einzuführen. Johannes M. Ruschke stellt den Kirchenstreit, seine Vorgeschichte, Bedeutung und Auswirkungen sowohl historisch als auch theologisch unter anderem auf der Basis bisher unbekannter oder unausgewerteter Quellen kritisch umfassend dar, analysiert und bewertet dessen Auswirkungen und bietet eine Edition wichtiger Voten Gerhardts.

Johannes M. Ruschke Geboren 1980; Studium der evangelischen Theologie in Bethel, Tübingen, Berlin und Münster; Vikariat in Dortmund-Wellinghofen/Evangelische Kirche von Westfalen; 2011 Promotion.
Jetzt bestellen:

https://mohrsiebeck.com/buch/paul-gerhardt-und-der-berliner-kirchenstreit-9783161520143?no_cache=1

order@mohrsiebeck.com

Telefon: +49 (0)7071-923-17

Telefax: +49 (0)7071-51104 